\title{
Compatibilidade de isolados de Beauveria bassiana (Ascomycetes: Clavicipitaceae) com carrapaticidas químicos utilizados no controle do carrapato dos bovinos
}

\author{
Compatibility of Beauveria bassiana (Ascomycetes: Clavicipitaceae) with chemicals
} acaricides used in the control of cattle tick

Leila A. G. Barci ${ }^{\text {** }}$ Inajá M. Wenzel²; José Eduardo M. de Almeida ${ }^{3}$; Adriana H. de Campos Nogueira ${ }^{4}$; Angelo P. do Prado

${ }^{1}$ Instituto Biológico, Centro de Pesquisa e Desenvolvimento de Sanidade Animal - CPDSA

${ }^{2}$ Toyobo do Brasil Ltda.

${ }^{3}$ Instituto Biológico, Centro Experimental do Instituto Biológico - CEIB

${ }^{4}$ Apta Regional, Polo Extremo Oeste

${ }^{5}$ Departamento de Parasitologia, Universidade Estadual de Campinas - UNICAMP

Recebido em 26 de Agosto de 2008

Aceito em 15 de Outubro de 2009

\section{Resumo}

O presente trabalho teve como escopo avaliar a compatibilidade dos isolados IBCB66 e IBCB21 de Beauveria bassiana com os carrapaticidas a base de Flumetrina + Coumafós, Deltametrina, Diclorvós + Cipermetrina, Diclorvós + Clorpirifós, Cipermetrina High Cis, Diclorvós + Cipermetrina High Cis, Cipermetrina e Amitraz utilizados no controle do carrapato Rhipicephalus (Boophilus) microplus em nosso país. O efeito dos produtos comerciais sobre os isolados foi verificado por meio da observação do crescimento vegetativo, produção de conídios e viabilidade das estirpes do fungo B. bassiana. Com referência ao isolado IBCB66, os produtos Deltametrina, Cipermetrina High Cis e Amitraz foram classificados como compatíveis, não interferindo no desenvolvimento do entomopatógeno. O produto Cipermetrina foi classificado como tóxico e os produtos Flumetrina + Coumafós, Diclorvós + Cipermetrina, Diclorvós + Clorpirifós e Diclorvós + Cipermetrina High Cis, muito tóxicos. Em relação ao isolado IBCB21, os produtos Flumetrina + Coumafós, Diclorvós + Cipermetrina, Diclorvós + Clorpirifós, Cipermetrina High Cis, Diclorvós + Cipermetrina High Cis e Cipermetrina foram classificados como muito tóxicos e o produto Amitraz como tóxico. Entre os carrapaticidas avaliados, o produto Deltametrina foi o único que não produziu efeito tóxico sobre o entomopatógeno.

Palavras-chave: Fungo entomopatogênico, produtos comerciais, crescimento vegetativo, esporulação, viabilidade de conídios.

\begin{abstract}
The purpose of the present study was to assess compatibility between IBCB66 and IBCB21 isolates of Beauveria bassiana and acaricides: Flumethrin + Coumaphos, Deltamethrin, Dichlorvos + Cypermethrin, Dichlorvos + Chlorpyrifos, Cypermethrin High Cis, Dichlorvos + Cypermethrin High Cis, Cypermethrin and Amitraz, utilized on the control of Rhipicephalus (Boophilus) microplus in our country. The effect of commercial products on the isolates was assayed according to observation of vegetative growth, conidia production, and viability of strains of B. bassiana fungus. With concerning about IBCB66 isolate, products Deltamethrin, Cypermethrin High Cis and Amitraz were compatible, not affecting the entomopathogen development. Product Cypermethrin was toxic, and products Flumethrin + Coumaphos, Dichlorvos + Cypermethrin, Dichlorvos+ Chlorpyrifos and Dichlorvos + Cypermethrin High Cis were very toxic. In regard to IBCB21 isolate, products Flumethrin + Coumaphos, Dichlorvos + Cypermethrin, Dichlorvos + Chlorpyrifos, Cypermethrin High Cis, Dichlorvos + Cypermethrin High Cis and Cypermethrin were very toxic and product Amitraz was toxic. From the acaricides evaluated, product Deltamethrin was the single agent that did not produce toxic effect on the entomopathogen.
\end{abstract}

Keywords: Entomopathogenic fungi, commercial products, vegetative growth, sporulation, conidial viability.

\footnotetext{
*Autor para correspondência: Leila Aparecida Gardiman Barci

Centro de Pesquisa e Desenvolvimento de Sanidade Animal - CPDSA,

Instituto Biológico, Av. Conselheiro Rodrigues Alves 1.252,

CEP 04.014-002, São Paulo - SP, Brasil

e-mail: barci@biologico.sp.gov.br
} 


\section{Introdução}

O carrapato Rhipicephalus (Boophilus) microplus é considerado um dos principais ectoparasitas que acomete bovinos em virtude dos prejuízos que causa à pecuária brasileira.

O controle do $R$. (B.) microplus é feito principalmente por meio de produtos químicos, aplicados sobre o animal, com objetivo de combater as fases parasitárias do carrapato. Problemas causados pelo uso indiscriminado de carrapaticidas, como a resistência, contaminação da carne e do leite, poluição do meio ambiente e intoxicação do homem, apontam a necessidade do emprego de sistemas integrados de controle (BARROS; EVANS, 1989). O domínio dessa situação a campo, em geral, é tratado com aumento crescente das dosagens dos produtos existentes no mercado (muito além das indicadas nos rótulos dos produtos), aumento na frequência de tratamentos dos animais ou composiçôes caseiras de formulaçôes. Essas situações contribuem sobremaneira no estabelecimento da resistência dos carrapatos às diferentes moléculas químicas. $\mathrm{O}$ impacto dessas medidas reverte em aumento de danos ao meio ambiente, risco a saúde do aplicador, dos animais e sua progênie e na inviabilização prematura dos produtos químicos oferecidos na praça (BAHIENSE; BITTENCOURT, 2004).

Atualmente, a busca por métodos alternativos é cada vez mais vislumbrada por profissionais responsáveis pelo controle desse ectoparasita. Entre as alternativas de controle disponíveis, o controle biológico pode apresentar-se como método promissor e auxiliar no combate do carrapato visando minimizar os problemas causados por esse ectoparasita (BARCI, 1997).

Entretanto, o sucesso de programas de controle, utilizando fungos entomopatogênicos, depende da sobrevivência dos conídios no meio ambiente (BENZ, 1987), que pode ser alterada por fatores climáticos, biológicos ou por produtos químicos.

A detecção de isolados compatíveis com compostos químicos de diferentes grupos é fundamental, pois o estabelecimento de enzootias, em populaçóes de artrópodes a campo, só se estabelecerá se não houver inibição de crescimento vegetativo do agente entomopatogênico que é a etapa inicial do processo (ALVES; MOINO JUNIOR; ALMEIDA, 1998).

$\mathrm{Na}$ área veterinária, poucos experimentos têm sido conduzidos no sentido de se verificar o efeito de produtos químicos sobre fungos entomopatogênicos.

Paiāo (2000) estudou a compatibilidade de vários isolados de Beauveria bassiana e Metarhizium anisopliae com carrapaticidas químicos utilizados a campo no controle de $R$. (B.) microplus e verificou que os produtos BUTOX ${ }^{\circledR}$, TRIATOX ${ }^{\circledR}$ E CYPERMIL PLUS $^{\circledR}$ influenciaram negativamente o crescimento do isolado JAB07 e que $B$. bassiana é mais sensível aos produtos químicos do que $M$. anisopliae.

Bahiense e Bittencourt (2004) ao simular, em condiçóes de laboratório, a associação do fungo $B$. bassiana à Deltametrina obteveram efeito sinérgico dessa combinação no tratamento de larvas de $R$. (B.) microplus resistentes a este grupo químico.

Tendo em vista a necessidade de estudos referentes ao controle biológico de $R$. (B.) microplus e que muitos agentes biológicos em composição com produtos químicos podem aumentar a eficiência do controle desse carrapato, por causa do efeito aditivo ou sinérgico obtido, o presente trabalho teve como objetivo verificar a ação tóxica de alguns carrapaticidas comerciais sobre os isolados IBCB66 e IBCB21 do fungo B. bassiana.

\section{Material e Métodos}

Foram utilizados os isolados IBCB66 e IBCB21 de B. bassiana procedentes do Banco de Microrganismos Entomopatogênicos "Oldemar Cardim Abreu" do Laboratório de Controle Biológico, Centro Experimental Central do Instituto Biológico localizado em Campinas, SP.

Informações sobre o nome comercial, ingrediente ativo, grupo químico, concentraçóes, dosagem recomendada e modo de administraçáo dos produtos químicos utilizados encontram-se representados no Quadro 1.

Quadro 1. Formulaçôes (carrapaticidas) utilizadas em testes de compatibilidade com os isolados IBCB66 e IBCB21 do fungo Beauveria bassiana realizados em condiçóes de laboratório.

\begin{tabular}{|c|c|c|c|c|c|}
\hline $\begin{array}{l}\text { Princípio } \\
\text { ativo }\end{array}$ & $\begin{array}{c}\text { Nome } \\
\text { comercial }\end{array}$ & $\begin{array}{c}\text { Grupo } \\
\text { químico }\end{array}$ & $\begin{array}{c}\text { Concentraçáo } \\
\text { PT*(Veículo q.s.p.) }\end{array}$ & $\begin{array}{c}\text { Dose } \\
\text { recomendada }(\mathrm{L} / \mathrm{L})\end{array}$ & Administraçáo \\
\hline $\begin{array}{c}\text { Flumetrina }+ \\
\text { Coumafós }\end{array}$ & Bovinal ${ }^{\circledR}$ & $\begin{array}{c}\text { Piretroide e } \\
\text { Organofosforado }\end{array}$ & $1,2 \mathrm{~g}+16 \mathrm{~g}(100 \mathrm{~mL})$ & $1 / 400$ & $\begin{array}{c}\text { Banheiros carrapaticidas } \\
\text { Pulverização }\end{array}$ \\
\hline Deltametrina & Butox ${ }^{\circledR} \mathrm{P}$ & Piretroide & $50 \mathrm{~g}(1000 \mathrm{~mL})$ & $1 / 2000$ & Pulverizaçâo \\
\hline $\begin{array}{c}\text { Diclorvós + } \\
\text { Cipermetrina }\end{array}$ & Cipermil Plus ${ }^{\circledR}$ & $\begin{array}{c}\text { Organofosforado } \\
\text { Piretroide }\end{array}$ & $45,0 \mathrm{~g}+5,0 \mathrm{~g}(100 \mathrm{~mL})$ & $1 / 400$ & Pulverização \\
\hline Diclórvos + Clorpirifós & Ectofós ${ }^{\circledR}$ & Organofosforado & $60,0 \mathrm{~g}+20,0 \mathrm{~g}(100 \mathrm{~mL})$ & $1 / 400$ & Pulverização \\
\hline Cipermetrina high cis & Ectomin $^{\circledR}$ & Piretroide & $10 \mathrm{~g}(100 \mathrm{~mL})$ & $1 / 1000$ & $\begin{array}{c}\text { Banheiros carrapaticidas } \\
\text { Pulverizaçáo }\end{array}$ \\
\hline $\begin{array}{c}\text { Diclorvós }+ \\
\text { Cipermetrina high cis }\end{array}$ & Ectoplus $^{\circledR}$ & $\begin{array}{c}\text { Organofosforado e } \\
\text { Piretroide }\end{array}$ & $44,7 \mathrm{~mL}+4,2 \mathrm{~mL}(100 \mathrm{~mL})$ & $1 / 400$ & Pulverização \\
\hline Cipermetrina & Flytick $^{\circledR}$ & Piretroide & $15 \mathrm{~g}(100 \mathrm{~mL})$ & $1 / 1000$ & $\begin{array}{c}\text { Banheiros carrapaticidas } \\
\text { Pulverizaçáo }\end{array}$ \\
\hline Amitraz & Triatox $^{\circledR}$ & Formamidina & $12,5 \mathrm{~g}(100 \mathrm{~mL})$ & $1 / 500$ & Pulverização \\
\hline
\end{tabular}

Fonte: Compêndio de produtos veterinários (SINDAN, http://www.cpvs.com.br/cpvs/index.html); ${ }^{* P T}$ - produto técnico. 
Para avaliação da compatibilidade, os isolados IBCB66 e IBCB21 do fungo B. bassiana foram repicados em meio de cultura batata-dextrose-agar (BDA) contendo os carrapaticidas nas doses recomendadas pelo fabricante.

Cada tratamento foi constituído por seis repetiçóes provenientes de três inoculaçóes em duas placas de Petri por produto. $\mathrm{O}$ tratamentotestemunha foi constituído por placas inoculadas com os isolados a serem testados, em meio de cultura pura sem o produto. As placas inoculadas foram mantidas em câmaras de germinação, a $26^{\circ} \mathrm{C}$, com fotoperíodo de 12 horas por um período de 12 dias.

Após o período de incubação, a compatibilidade foi avaliada por meio dos parâmetros: tamanho da colônia (crescimento vegetativo) e número de conídios produzidos (crescimento reprodutivo ou esporulação).

O crescimento vegetativo foi avaliado com uma régua milimétrica, medindo-se as colônias em dois sentidos e retirando-se a média das duas medidas.

Para contagem do número de conídios, as colônias foram recortadas juntamente com o meio de cultura e transferidas para tubos de ensaio de vidro $(8,5 \mathrm{~cm}$ de altura $\times 2,5 \mathrm{~cm}$ de diâmetro), contendo $10 \mathrm{~mL}$ de água destilada estéril com espalhante adesivo (Tween $80^{\circledR}$ ). As suspensóes do microrganismo foram diluídas e quantificadas por meio de contagem direta ao microscópio com auxílio de câmara de Neubauer (ALVES; MORAES, 1998). O cálculo do fator de compatibilidade dos produtos carrapaticidas foi feito pela Equação 1 proposta por Alves, Moino Junior e Almeida (1998):

$$
\mathrm{T}=\frac{20(\mathrm{CV})+80(\mathrm{ESP})}{100}
$$

onde $\mathrm{T}$ = valor corrigido do crescimento vegetativo e esporulação para classificação do produto; $\mathrm{C}$.V. = porcentagem do crescimento vegetativo com relação à testemunha) e ESP = (porcentagem de esporulação com relação à testemunha).

A viabilidade foi avaliada por meio de inoculação e contagem de conídios em placa, contendo BDA, por meio de exame direto em microscópio.

Para realização do ensaio, foi utilizado $0,1 \mathrm{~mL}$ com $10^{5}$ conídios. $\mathrm{mL}^{-1}$ de cada suspensão fúngica, procedente das colônias formadas nas placas incubadas, com os acaricidas testados. Depois de proceder ao plaqueamento, as placas foram incubadas a $26 \pm 1{ }^{\circ} \mathrm{C}$ durante 16 horas. Após esse período, cada placa foi dividida em 4 quadrantes e, em cada um, foram realizadas a observação e contagem de conídios em um campo, escolhido aleatoriamente, em cada área delimitada. Foram considerados conídios germinados e não germinados, estabelecendo-se depois a porcentagem de germinação. Cada placa correspondeu a um tratamento e cada quadrante a uma repetição, totalizando quatro parcelas para cada grupo tratado.

Os resultados obtidos foram analisados por ANOVA. As médias foram comparadas pelo teste de comparação múltipla de Tukey a 5\% de significância.

\section{Resultados}

\section{1. $I B C B 66$}

Crescimento vegetativo: os resultados obtidos (Tabela 1) apontaram médias de crescimento radial de colônias do isolado IBCB66 de $B$. bassiana entre 1,56 a $3,58 \mathrm{~cm}$ no grupo controle e nos meios acrescidos dos produtos Deltametrina, Cipermetrina High Cis, Diclorvós +

Tabela 1. Médias do crescimento vegetativo, esporulação e viabilidade dos isolados IBCB21 e IBCB66 de Beauveria bassiana, em meios de cultura com carrapaticidas comumente utilizados no controle de Rhipicephalus (Boophilus) microplus.

\begin{tabular}{|c|c|c|c|c|c|c|c|c|c|c|c|c|c|}
\hline \multirow[b]{2}{*}{ Tratamentos } & \multicolumn{7}{|c|}{ IBCB66 } & \multicolumn{6}{|c|}{ IBCB21 } \\
\hline & \multicolumn{2}{|c|}{$\begin{array}{c}\text { Crescimento } \\
\text { vegetativo } \\
(\mathrm{cm})\end{array}$} & \multicolumn{3}{|c|}{$\begin{array}{l}\text { Número de } \\
\text { conídios } \\
\left(10^{7} \cdot \mathrm{mL}^{-1}\right)\end{array}$} & \multicolumn{2}{|c|}{$\begin{array}{l}\text { Viabilidade } \\
(\%)\end{array}$} & \multicolumn{2}{|c|}{$\begin{array}{l}\text { Crescimento } \\
\text { vegetativo } \\
(\mathrm{cm})^{1}\end{array}$} & \multicolumn{2}{|c|}{$\begin{array}{l}\text { Número de } \\
\text { conídios } \\
\left(10^{7} \cdot \mathrm{mL}^{-1}\right)\end{array}$} & \multicolumn{2}{|c|}{$\begin{array}{c}\text { Viabilidade } \\
(\%)\end{array}$} \\
\hline Testemunha & $3,58 \pm 0,0753$ & $\mathrm{a}$ & & $8,39 \pm 0,9731$ & $\mathrm{ab}$ & $97,5 \pm 0,5000$ & $\mathrm{a}$ & $2,25 \pm 0,3162$ & $\mathrm{bc}$ & $27,90 \pm 22,2716$ & $\mathrm{a}$ & $94,3 \pm 2,0207$ & $\mathrm{a}$ \\
\hline $\begin{array}{c}\text { Flumetrina + } \\
\text { Coumafós }\end{array}$ & - & - & & - & - & - & - & - & - & - & - & - & - \\
\hline Deltametrina & $2,73 \pm 0,1294$ & $\mathrm{~b}$ & & $9,63 \pm 2,9990$ & $\mathrm{a}$ & $89,5 \pm 6,0622$ & $\mathrm{a}$ & $3,21 \pm 0,4852$ & a & $14,57 \pm 2,609$ & $a b$ & $97,5 \pm 1,5000$ & $\mathrm{a}$ \\
\hline $\begin{array}{c}\text { Diclorvós + } \\
\text { Cipermetrina }\end{array}$ & - & - & & - & - & - & - & $1,74 \pm 0,2084$ & c & $3,71 \pm 0,9857$ & $\mathrm{~cd}$ & $94,8 \pm 2,4664$ & $\mathrm{a}$ \\
\hline $\begin{array}{c}\text { Diclórvos + } \\
\text { Clorpirifós }\end{array}$ & - & - & & - & - & - & - & - & - & - & - & - & $\ldots$ \\
\hline $\begin{array}{c}\text { Cipermetrina } \\
\text { High Cis }\end{array}$ & $2,08 \pm 0,2382$ & & & $8,3 \pm 3,2286$ & $\mathrm{a}$ & $95,5 \pm 2,8284$ & $\mathrm{a}$ & - & - & - & - & - & - \\
\hline $\begin{array}{c}\text { Diclorvós + } \\
\text { Cipermetrina } \\
\text { High Cis }\end{array}$ & $1,56 \pm 0,0492$ & & d & $0,02 \pm 0,0052$ & c & $88,2 \pm 10,0540$ & $\mathrm{a}$ & $3,38 \pm 0,6601$ & a & $0,71 \pm 0,3357$ & $\mathrm{~cd}$ & $87,2 \pm 9,5289$ & $\mathrm{a}$ \\
\hline Cipermetrina & $2,79 \pm 0,2108$ & b & & $2,44 \pm 1,6369$ & $\mathrm{~b}$ & $92,3 \pm 2,5166$ & $\mathrm{a}$ & $2,71 \pm 0,2438$ & $\mathrm{ab}$ & $0,15 \pm 0,0420$ & d & $96,6 \pm 2,9297$ & $\mathrm{a}$ \\
\hline Amitraz & $1,63 \pm 0,0418$ & & d & $6,04 \pm 0,5012$ & $\mathrm{a}$ & $85,2 \pm 4,5369$ & $\mathrm{a}$ & $2,22 \pm 0,3204$ & bc & $6,48 \pm 2,9438$ & bc & $98,6 \pm 1,5275$ & $\mathrm{a}$ \\
\hline Teste F & $166,88^{*}$ & & & $37,73^{*}$ & & $1,8794^{\text {n.s. }}$ & & $13,98^{*}$ & & $16,02^{*}$ & & $2,88^{\text {n.s. }}$ & \\
\hline C.V. (\%) & 2,58 & & & 16,29 & & 3,24 & & 6,79 & & 38,12 & & 2,26 & \\
\hline
\end{tabular}

${ }^{1}$ Médias seguidas de mesma letra minúscula, nas colunas, não diferem estatisticamente entre si; ${ }^{*}$ Significativo a $5 \%$ de probabilidade pelo Teste $\mathrm{F}$. 
Cipermetrina High Cis, Cipermetrina e Amitraz e do grupo controle $(3,58 \mathrm{~cm})$. Os meios que continham os produtos Flumetrina + Coumafós, Diclorvós + Cipermetrina e Diclorvós + Clorpirifós não apresentaram crescimento vegetativo de colônias do fungo entomopatogênico. A análise estatística dos dados (Tabela 1) indicou que não houve diferença estatística entre o crescimento vegetativo do isolado IBCB66 obtido nos grupos tratados com os produtos Deltametrina e Cipermetrina. O mesmo fato pode ser observado nos tratamentos com os produtos Diclorvós + Cipermetrina High Cis e Amitraz. Entretanto, o crescimento vegetativo do entomopatógeno, obtido nos tratamentos com os produtos Deltametrina e Cipermetrina, divergiu estatisticamente daqueles que foram plaqueados em meios contendo os produtos Diclorvós + Cipermetrina High Cis e Amitraz. O grupo tratado com o produto Cipermetrina High Cis apresentou crescimento vegetativo estatisticamente divergente dos demais tratamentos que compuseram o bioensaio. Todos os tratamentos realizados diferiram do grupo-controle que apresentou crescimento radial médio de $3,58 \mathrm{~cm}$, superior ao apurado nos diversos tratamentos com produtos químicos. Os dados procedentes dos tratamentos com o produto Flumetrina + Coumafós, Diclorvós + Cipermetrina e Diclorvós + Clorpirifós, que náo apresentaram crescimento vegetativo, não foram computados na análise estatística.

Esporulaçáo (número de conídios): os resultados obtidos (Tabela 2) indicaram médias de esporulação de conídios do isolado IBCB66 de $B$. bassiana entre $2 \times 10^{5}$ e 9,63 × $10^{7}$ conídios. $\mathrm{mL}^{-1}$ no grupo controle e nos meios acrescidos dos produtos Deltametrina, Cipermetrina High Cis, Diclorvós + Cipermetrina High Cis, Cipermetrina e Amitraz. O grupo-controle apresentou índice de esporulação de $8,39 \times 10^{7}$ conídios. $\mathrm{mL}^{-1}$, estatisticamente indistinto dos grupos tratados com os produtos Deltametrina, Cipermetrina High Cis e Amitraz. Os meios que continham os produtos Flumetrina + Coumafós, Diclorvós + Cipermetrina e Diclorvós + Clorpirifós, por não apresentarem crescimento vegetativo de colônias do fungo entomopatogênico, consequentemente, não produziram conídios. A análise estatística dos dados, por meio do cálculo do teste de Tukey, mostrou que, em relação à esporulação do isolado IBCB66, houve diferença estatística entre os grupos cujos meios de cultura continham os produtos Cipermetrina e Diclorvós + Cipermetrina High Cis. A diferença estatística foi apurada tanto entre si como com referência aos demais tratamentos do bioensaio. Os dados procedentes dos tratamentos com os produtos Flumetrina + Coumafós, Diclorvós + Cipermetrina e Diclorvós + Clorpirifós, que não apresentaram esporulação, não foram computados na análise estatística.

Viabilidade: os dados apurados mostraram percentuais de viabilidade entre 97,6 e $85,2 \%$ nos seis tratamentos com os diferentes acaricidas e no grupo controle (94,3\%). A análise estatística dos dados, por meio do cálculo do teste de Tukey, indicou que não houve diferença estatística entre os percentuais de viabilidade obtidos nos grupos tratados, tanto entre si como em relaçáo ao grupo controle (Tabela 1).

\section{IBCB21}

Crescimento vegetativo: Os resultados obtidos (Tabela 2) mostraram médias de crescimento radial de colônias do isolado IBCB21 de $B$. bassiana entre $1,74 \mathrm{~cm}$ a $3,38 \mathrm{~cm}$ no grupo controle e nos meios acrescidos dos carrapaticidas Deltametrina, Diclorvós +
Cipermetrina, Diclorvós + Cipermetrina High Cis, Cipermetrina e Amitraz. O grupo-controle apresentou crescimento radial das colônias $(2,25 \mathrm{~cm})$ inferior aos grupos tratados com os produtos Deltametrina, Diclorvós + Cipermetrina High Cis e Cipermetrina. Os meios que continham os produtos Flumetrina + Coumafós, Diclorvós + Clorpirifós e Cipermetrina High Cis não apresentaram crescimento vegetativo de colônias do entomopatógeno. Os grupos, nos quais foram incorporados aos meios de cultura os carrapaticidas Deltametrina, Diclorvós + Cipermetrina High Cis e Cipermetrina, não apontaram divergências estatísticas entre si. As placas que continham o produto Cipermetrina, entretanto, também apresentaram índices de crescimento vegetativo estatisticamente concordantes com aquelas que compunham o grupo-controle e com as que receberam o produto Amitraz. $\mathrm{O}$ mesmo fato pode ser apurado nos tratamentos com os produtos Diclorvós + Cipermetrina, Amitraz e o grupo controle. Os dados procedentes dos tratamentos com os produtos Flumetrina + Coumafós, Diclorvós + Clorpirifós e Cipermetrina High Cis, que não apresentaram crescimento vegetativo, não foram computados na análise estatística.

Esporulaçáo (número de conídios): os resultados obtidos (Tabela 1) indicaram médias de esporulação de conídios do isolado IBCB21 de B. bassiana entre $1,5 \times 10^{6}$ a $2,79 \times 10^{8}$ conídios. $\mathrm{mL}^{-1}$ no- grupo controle e nos meios acrescidos dos carrapaticidas Deltametrina, Diclorvós + Cipermetrina, Diclorvós + Cipermetrina High Cis, Cipermetrina e Amitraz. O grupo controle apresentou índice de esporulação de $2,79 \times 10^{8}$ conídios. $\mathrm{mL}^{-1}$, superior aos grupos tratados com Deltametrina, Diclorvós + Cipermetrina, Diclorvós + Cipermetrina High Cis, Cipermetrina e Amitraz. Os meios que continham os produtos Flumetrina + Coumafós, Diclorvós + Clorpirifós e Cipermetrina High Cis não apresentaram crescimento vegetativo de colônias do fungo entomopatogênico e, consequentemente, não produziram conídios. A análise estatística dos dados, por meio do cálculo do teste de Tukey, indicou que não houve diferença estatística entre o número de conídios do isolado IBCB21 obtido no grupo controle e no tratado com o produto Deltametrina. Este, por sua vez, não divergiu do isolado que foi inoculado em meio contendo o produto Amitraz o qual apresentou concordância com os grupos que tinham incorporado, no meio de cultura, os acaricidas Diclorvós + Cipermetrina e Diclorvós + Cipermetrina High Cis. Os grupos, nos quais foram incorporados aos meios de cultura os carrapaticidas Diclorvós + Cipermetrina e Diclorvós + Cipermetrina High Cis, não apontaram divergências estatísticas daqueles que continham o produto Cipermetrina. Os dados procedentes dos tratamentos com os produtos Flumetrina + Coumafós, Diclorvós + Clorpirifós e Cipermetrina High Cis, que não apresentaram esporulação, não foram computados na análise estatística.

Viabilidade: os dados apurados (Tabela 1) mostraram percentuais de viabilidade entre 87,2 e $98,6 \%$ nos seis tratamentos com os diferentes acaricidas e, no grupo controle, (94,3\%). A análise estatística dos dados, por meio do cálculo do teste de Tukey, indicou que não houve diferença estatística entre os percentuais de viabilidade obtidos nos grupos tratados, tanto entre si como em relação ao grupo-controle (Tabela 1).

Classificaçáo dos carrapaticidas de acordo com valores de T: as informaçóes referentes à classificação da compatibilidade dos carrapaticidas comerciais frente aos isolados IBCB21 e IBCB66 do fungo entomopatogênico $B$. bassiana encontram-se reunidas na Tabela 2 . 
Tabela 2. Valores de T e classificação dos produtos utilizados no controle de Rhipicephalus (Boophilus) microplus em relação aos isolados IBCB66 e IBCB21 de Beauveria bassiana.

\begin{tabular}{|c|c|c|c|c|}
\hline \multirow{2}{*}{ Princípio ativo } & \multicolumn{2}{|c|}{ IBCB66 } & \multicolumn{2}{|c|}{ IBCB21 } \\
\hline & Valor de $\mathrm{T}$ & Classificação* & Valor de T & Classificaçáo* \\
\hline Flumetrina + Coumafós & 0,0 & MT & 0,0 & MT \\
\hline Deltametrina & 107,1 & $\mathrm{C}$ & 70,3 & $\mathrm{C}$ \\
\hline Diclorvós + Cipermetrina & 0,0 & MT & 26,1 & MT \\
\hline Diclórvos + Clorpirifós & 0,0 & MT & 0,0 & MT \\
\hline Cipermetrina high cis & 90,8 & $\mathrm{C}$ & 0,0 & MT \\
\hline Diclorvós + Cipermetrina high cis & 8,9 & MT & 32,1 & MT \\
\hline Cipermetrina & 38,9 & $\mathrm{~T}$ & 24,5 & MT \\
\hline Amitraz & 66,7 & $\mathrm{C}$ & 38,3 & $\mathrm{~T}$ \\
\hline
\end{tabular}

${ }^{*} \mathrm{C}=$ compatível; $\mathrm{MT}=$ muito tóxico; $\mathrm{T}=$ tóxico.

\section{Discussáo}

Os isolados IBCB66 e IBCB21 do fungo B. bassiana náo apresentaram o mesmo padrão de resposta quanto à compatibilidade, quando avaliados em meios de cultura acrescidos de carrapaticidas comerciais nas dosagens recomendadas pelo fabricante.

Provavelmente, as diferenças observadas nos parâmetros analisados dependeram principalmente do isolado, natureza química dos componentes, formulação e concentração do produto empregado.

Os resultados obtidos permitiram inferir que os isolados IBCB66 e IBCB21 de B. bassiana são altamente suscetíveis à ação de carrapaticidas que contenham moléculas de organofosforados, uma vez que todos os tratamentos realizados com produtos que continham esses ingredientes ativos produziram efeito muito tóxico sobre o fungo. Provavelmente, os carrapaticidas constituídos por compostos organofosforados inibiram a enzima responsável pela formação da parede celular, interferindo sobremaneira na germinação dos conídios (GHINI; KIMATI, 2000), fato que náo foi observado nos tratamentos com outros produtos.

Essas observaçóes vão ao encontro das relatadas por Oliveira e Neves (2004), que, ao realizar experimentaçôes sobre compatibilidade de Beauveria bassiana a acaricidas utilizados na área agrícola, constataram que formulaçôes pertencentes ao grupo químico dos organofosforados afetaram drasticamente a germinaçáo de conídios, bem como a esporulação de isolados de B. bassiana.

Não obstante, as informaçôes publicadas pelos mesmos autores, referentes a produtos à base de Amitraz, discordam, em parte, dos descritos no presente trabalho. Os bioensaios mostraram que o IBCB66 não apresentou diferenças significativas quanto aos resultados obtidos entre o tratamento com o produto composto por moléculas de Amitraz e a testemunha, quanto à esporulaçáo e viabilidade de conídios, fatos não observados por Oliveira e Neves (2004).

Ainda em relação ao Amitraz, trabalhos conduzidos por Paiāo (2000), em experimentaçóes com Beauveria bassiana, isolado JAB07, indicaram que compostos à base de amidina podem ser nocivos a esse fungo. Os resultados obtidos pelo autor supracitado mostraram uma significativa redução no crescimento vegetativo, esporulaçáo e viabilidade de conídios do isolado JAB07 de B. bassiana em meios de cultura, acrescidos com produto em subdosagens ou na dosagem recomendada pelo fabricante.

Essas evidências permitem inferir que o isolado IBCB66 é particularmente tolerante às formulaçôes à base de Amitraz. $\mathrm{O}$ mesmo fato náo pode ser extrapolado ao isolado IBCB21 que, em condiçóes de laboratório, apresentou mesmo padrão de crescimento vegetativo em relação ao grupo controle, mas, com referência à esporulação, apresentou valores numéricos significativamente inferiores quando comparado à testemunha.

Analisando-se os resultados de compatibilidade obtidos nos tratamentos com produtos à base de piretróides, pode-se deduzir que, de maneira geral, carrapaticidas compostos por ingredientes ativos desse grupo foram bem tolerados pelo isolado IBCB66 de B. bassiana. Com relação ao isolado IBCB21, o mesmo fato náo é verdadeiro, principalmente quando se trata de produtos à base de Cipermetrina.

Traçando-se um paralelo entre as informaçôes publicadas por Oliveira e Neves (2004) e os dados obtidos neste estudo, foi possível perceber que há concordância quanto à hipótese de que os piretroides não devem constituir-se como fator restritivo à utilização associada dos produtos dessa classe química e os isolados IBCB66 e IBCB21 de B. bassiana, principalmente com referência a produtos à base de Deltametrina.

Considerando-se os resultados obtidos com o produto Deltametrina, nos bioensaios conduzidos com os dois isolados estudados no presente trabalho, pode-se observar que não houve diferença estatística significativa entre os parâmetros obtidos entre o grupo-controle e o tratado com Deltametrina no que se refere à germinação, esporulação e viabilidade dos conídios.

Todavia, as mesmas conclusóes náo se aplicam às descriçóes apontadas por Paiâo (2000), que obteve efeito tóxico ao produto Deltametrina sobre o crescimento radial das colônias de $B$. bassiana as quais foram evidenciadas logo no início do período de cultivo. Segundo o autor, no terceiro dia após a inoculação, com exceção do tratamento com $20 \%$ da dosagem do produto recomendada pelo fabricante, todos os demais se diferenciaram do grupo controle com significativa redução do crescimento do fungo. Também foi constatada a diminuição da viabilidade de conídios do isolado testado. Os mesmos efeitos também foram apontados por Alzogaray et al. (1998), em experimentaçôes conduzidas com o intento de verificar a açáo de deltametrina sobre $B$. bassiana. 
Analisando-se os resultados demonstrados nas experimentaçóes com Cipermetrina (Tabela 2), foi possível deduzir que o efeito do produto Cipermetrina sobre os isolados IBCB21 e IBCB66, nos diferentes estágios do fungo, é dependente de condiçôes particulares de cada estirpe, uma vez que o grau de toxicidade foi distinto para cada isolado de $B$. bassiana.

O produto Diclorvós + Cipermetrina apresentou efeito altamente tóxico sobre IBCB66 e IBCB21. Sobre IBCB66 produziu efeito deletério, inviabilizando o crescimento vegetativo, produção de conídios e, consequentemente, a viabilidade dos conídios após 12 dias de observação. Com relação ao isolado IBCB21, apesar de ter produzido efeito tóxico, possibilitou a constataçáo desses parâmetros nas colônias tratadas, fato que ratifica e reforça a hipótese da dependência direta entre o isolado do fungo e a compatibilidade com os diferentes produtos químicos.

Analisando-se os resultados obtidos nos tratamentos com outros carrapaticidas compostos por associaçóes de moléculas de piretroides e organofosforados, pode-se perceber os mesmos efeitos sobre as etapas envolvidas no crescimento, multiplicação e viabilidade do fungo. Provavelmente, o efeito dos tratamentos sobre a germinação e esporulação do fungo deve ser atribuído à ação do ingrediente organofosforado.

Tratamentos conduzidos com o Cipermetrina High Cis foram classificados como compatíveis frente ao isolado IBCB66. Levando-se em conta o crescimento vegetativo, foi possível observar diferença estatística significativa em relação ao grupo-controle. Entretanto, a esporulação e viabilidade dos conídios de $B$. bassiana não foram afetadas. Considerando-se o isolado IBCB21, verificou-se um comportamento diametralmente oposto, uma vez que o grupo que recebeu tratamento com esse carrapaticida apresentou dados rigorosamente negativos em todos os parâmetros analisados.

As conclusóes sobre o piretroide acima concordam, em parte, com as reportadas por Paiáo (2000), que obteve redução no crescimento de $B$. bassiana, durante todo o período de cultivo, esporulação não prejudicada pelo tratamento e viabilidade afetada negativamente.

$\mathrm{O}$ produto Cipermetrina, quando analisado sob o aspecto do isolado IBCB66, demonstrou comportamento intermediário entre o produto Diclorvós + Cipermetrina e o Cipermetrina High Cis. O efeito tóxico de produtos químicos sobre fungos entomopatogênicos, observado em condiçóes de laboratório, pode apresentar-se mais compatível quando as misturas são utilizadas em condiçóes de campo (informação verbal)*. Embora em condiçóes de laboratório o produto tenha se mostrado tóxico e interferido parcialmente no crescimento vegetativo, produção e viabilidade de conídios, a campo, estes mesmos podem apresentar comportamento diferente ao imputado sob condiçóes controladas. Porém, a mesma inferência não é válida para o isolado IBCB21 que demonstrou ser muito sensível aos compostos comerciais supracitados.

A avaliaçáo da compatibilidade em laboratório é vantajosa devido à exposição máxima do microrganismo à ação do produto químico, fato que não ocorre em condiçôes de campo. Dessa forma, não há dúvidas sobre a seletividade do produto em campo, quando constatada sua inocuidade em laboratório. Por outro lado, a alta toxicidade in vitro nem sempre indica a sua elevada toxicidade em campo (MOINO JUNIOR; ALVES, 1998), fator a ser considerado quando se trata de montar estratégias de controle integrado.

•Informação verbal de Antonio Batista Filho

\section{Conclusóes}

A viabilidade dos conídios dos isolados IBCB66 e IBCB21 de Beauveria bassiana não foi prejudicada pelos carrapaticidas; o isolado IBCB66 é mais tolerante aos carrapaticidas que o IBCB21; o IBCB66 pode ser utilizado, em formulações específicas, em associaçôes com moléculas sintéticas de produtos à base de Deltametrina e Cipermetrina High Cis e Amitraz; o isolado IBCB21 pode ser utilizado, em formulaçôes específicas, em associaçóes com moléculas sintéticas de produtos à base de deltametrina; associaçóes entre os isolados IBCB66 e IBCB21 e produtos compostos por organofosforados não são indicadas para a utilizaçáo no controle de carrapatos a campo; o isolado IBCB66 é o que apresenta maior indicação de emprego em associaçôes com carrapaticidas comerciais à base de diferentes grupos químicos.

\section{Referências}

ALVES, S. B.; MOINO, J. R.; ALMEIDA, J. E. M. Produtos fitossanitários e entomopatógenos. In: Controle Microbiano de Insetos. 2 ed. Piracicaba: FEALQ, 1998. p. 217-238.

ALVES, S. B.; MORAES, S. A. Quantificação de inóculo de patógenos de insetos. In: ALVES, S. B. (Ed.). Controle Microbiano de Insetos. 2.ed. Piracicaba: FEALQ, 1998. p. 765-777.

ALZOGARAY, R. et al. Effect of deltamethrin on germination and virulence of Beauveria bassiana (Bals.) Vuill. on Triatoma infestans (Klug.) Anais da Sociedade Entomologica do Brasil, v. 27, n. 4, p. 663-667, 1998.

BAHIENSE, T. C.; BITTENCOURT, V. R. E. P. Laboratory evaluation of the compatibility and the synergism between the entomopathogenic fungus Beauveria bassiana and deltamethrin to resistant strains of Boophilus microplus. Annals of the New York Academy of Sciences, v. 1026, p. 319-322, 2004.

BARCI, L. A. G. Controle biológico do carrapato dos bovinos Boophilus microplus (Acari, Ixodidae) no Brasil. Arquivos do Instituto Biológico, v. 64, n. 1, p. 95-101, 1997.

BARROS, T. A. M.; EVANS, D. E. Ação de gramíneas forrageiras em larvas infestantes do carrapato dos bovinos, Boophilus microplus. Pesquisa Veterinaria Brasileira, v. 9, n. 1/2, p. 17-21, 1989.

BENZ, G. Environment. In: FUXA, T.; TANADA, Y. (Eds.). Epizootiology of insect diseases. New York: Wiley, 1987. p. 177-214.

GHINI, R.; KIMATI, H. Resistência de fungos a fungicidas. Jaguariúna: EMBRAPA Meio Ambiente, 2000. 78 p.

MOINO JUNIOR, A.; ALVES, S. B. Efeito de Imidacloprid e Fipronil sobre Beauveria bassiana (Bals.) Vuill. e Metarbizium anisopliae (Metsch.) Sorok. e no comportamento de limpeza de Heterotermes tennuis (Hagen). Anais da Sociedade Entomológica do Brasil, v. 27, n. 4, p. 611-620, 1998.

OLIVEIRA, R. C.; NEVES, P. M. O. J. Compatibility of Beauveria bassiana with acaricides. Neotropical Entomology, v. 33, n. 3, p. 353-358, 2004.

PAIÃO, J. C. V. Compatibilidade dos fungos Beauveria bassiana e Metarhizium anisopliae com carrapaticidas químicos utilizados no controle de Boophilus microplus (Acari: Ixodidae). Jaboticabal, 2000. 55 p. Dissertação (Mestrado em Microbiologia) - Faculdade de Ciências Agrárias e Veterinárias, UNESP.

SINDICATO NACIONAL DA INDÚSTRIA DE PRODUTOS PARA SAÚDE ANIMAL - SINDAN. Compêndio de produtos veterinários. Disponível em: <http://www.sindan.org.br/sd/sindan/index.html >. Acesso em: 2007. 